Article

\title{
U.S. Sustainable Food Market Generation Z Consumer Segments
}

\author{
Ching-Hui (Joan) Su ${ }^{1}{ }^{*}$, Chin-Hsun (Ken) Tsai ${ }^{1}$, Ming-Hsiang Chen ${ }^{2,3}$ (D) and Wan Qing Lv ${ }^{4}$ \\ 1 Department of Apparel, Events, and Hospitality Management, College of Human Sciences, Iowa State \\ University, Ames, IA 50011-1078, USA \\ 2 Tourism and Social Administration College, Nanjing Xiaozhuang University, Nanjing 211171, China \\ 3 School of Hospitality Business Management, Carson College of Business, Washington State University, \\ Pullman, WA 99164-4742, USA \\ 4 School of Business and Tourism Management, Yunnan University, Kunming 650091, China \\ * Correspondence: joansu@iastate.edu
}

Received: 15 April 2019; Accepted: 28 June 2019; Published: 30 June 2019

check for updates

\begin{abstract}
This study explores the interaction between environmental consciousness and sustainable food attributes as predictors in the market segmentation process for sustainable foods with respect to United States (U.S.) Generation Z (Gen Z) consumers. This study was executed using a cross-national, web-based survey to analyze and categorize Gen $Z$ female $(n=435)$ and male $(n=377)$ consumers between 18 and 23 years of age living in the continental United States. The objectives of this study were to classify U.S. Gen Z consumers into unique segments based on their environmental consciousness and to assess the functional relationships among the following: (a) their degree of ecological awareness; (b) the importance of the perception of sustainable food attributes; (c) their food choices associated with healthy eating habits; and (d) sociodemographics. Survey data were analyzed using cluster analysis of consumer groups based on environmental consciousness. Environmental consciousness was measured using a composite score of the environmental involvement scale and the environmental values scale. Gen $Z$ consumers with high environmental consciousness (sustainable activists) and moderate ecological awareness (sustainable believers) considered more eco-friendly and healthy product attributes when purchasing sustainable food, whereas Gen Z consumers with low environmental consciousness (sustainable moderates) considered more extrinsic product attributes (e.g., price and convenience). Furthermore, the results indicate that food choices associated with healthy eating habits could be used to develop a profile for different eco-conscious Gen $\mathrm{Z}$ consumer groups. The contributions of this study are twofold. First, for academic researchers, this paper extends marketing segmentation research concerning environmentally sensitive young consumers. Second, for industry professionals, this study provides food retailers or food service operators with sustainable consumer values that will aid in the development of effective, green marketing strategies to better attract and meet the sustainability expectations of Gen Z-the consumer segment with the most spending power of any generation.
\end{abstract}

Keywords: Generation Z; market segmentation; sustainable food attributes

\section{Introduction}

As environmental concerns become increasingly crucial for companies to consider with respect to all consumer sectors, global consciousness about the balance between economic development and environmental conservation has moved consumers to embrace sustainable lifestyles, as well as to accept sustainable consumption patterns [1,2]. Food consumption is an essential and unavoidable part of everyday life, and it is an area where personal consumption is closely related to environmental 
sustainability [3]. Consumer movements that embrace environmentally friendly consumption issues (e.g., green restaurants and locavore food initiatives (Based on the conceptual background and literature review, the following definition was used to standardize the frame of locavore food for this study: farmers/producers selling food/food products directly to consumers at regional farmers' markets, schools, and retail/food service (United States Department of Agriculture, 2010).) that balance healthy, sustainable dining practices have emerged as a result of a growing environmental consciousness [4-7]. Thus, advocating the adoption of eco-friendly food consumption behavior, such as choosing products that have been manufactured in an eco-friendly way [8-10], is seen as a viable means of moving toward sustainable development [3,11,12].

Generation Z (Gen Z), also called Post-Millennials, are individuals born in 1995 or later [13]. As the newest generation, they currently constitute nearly 74 million people [14] in the United States (U.S.). Due to their early introduction to healthy lifestyle choices, research shows that Gen Z's are much more knowledgeable on sustainable living than previous generations [15]. Those within the Gen $\mathrm{Z}$ cohort tend to be eco-friendlier (i.e., concerned about the environment [16]), prioritize health when making food choices [17], and desire a higher quality of life in comparison to other generational cohorts. A Global Health and Wellness Survey of 30,000 people in 60 countries conducted by Nielsen (2015) [18] reported that $41 \%$ of Gen $\mathrm{Z}$ were willing to pay a premium for foods they perceive to be healthier, compared with $32 \%$ of Millennials (age 21-34) and about $21 \%$ of Baby Boomers (approximately age 50-mid-60s). Economists predict that Gen Z will contribute 29-143 billion U.S. dollars to the U.S. economy [19] and will become the largest share of the consumer market by 2020 [19-21]. Those statistics make a compelling case for a deeper study of the market segmentation factors that influence Gen Z's purchasing decisions in the sustainable food market.

U.S. consumer awareness of health, wellness, and environmentalism has increased $[8,10,22]$. In fact, many companies doing business in today's eco-conscious world will find that sustainability is not an option; it is a necessity. [23]. The green market is currently worth $\$ 227$ billion a year and is projected to reach $\$ 1$ trillion annually by 2020. A market report that tracks green economic trends conducted by the Natural Marketing Institute [24] found that about 30\% of U.S. adults purchase goods and services with consideration of the product's health, environmental, social justice, and sustainability value. This does not mean that $30 \%$ of the food consumed is organic or local or that $30 \%$ of cars purchased are hybrids and so on; however, it does imply that a significant percentage of consumers in the U.S. take into account environmental considerations when making a purchase [25]. The expanding mainstream green consumer market in the U.S. presents academic as well as business research opportunities that focus on the degree to which green style aligns with consumption behavior.

From a green consumption perspective, opportunities for policymakers and businesses to develop more environmentally sustainable consumption and production systems depend upon consumers' willingness to engage in green consumption behavior. With an emphasis on consumers, research efforts have largely sought to identify green consumers and develop meaningful green market segmentation practices that will appeal to these consumers [26,27]. Consumer interest in sustainable products and environmentally friendly business practices continues to grow [28], with consumers increasingly understanding that purchasing behaviors and product decisions can positively impact ecological issues [29]. Environmental literacy — the degree to which consumers understand ecological problems and their ability to make relevant connections between the products they consume and ecological issues-is critical information that factors into green consumption and sustainable development strategies [30,31].

While there is a great deal of scholarly consumer research concerning the environmentally friendly purchasing behavior of other generations (e.g., Baby Boomers and Generation Y) [32-34], Gen Z is relatively unexplored. To address this gap in understanding, the primary purpose of this study is to segment U.S. Gen Z into unique groups based on environmental consciousness. The second goal is to identify and describe the consumer groups' individual profile elements, including (a) the importance of the perception of sustainable food attributes, (b) the emphasis placed on sustainable food choices, 
and (c) sociodemographic characteristics. In doing so, findings could assist in establishing profiles for Gen Z consumer groups based on the level of importance placed on the purchase of sustainable foods and the factors that influence those purchases. The results have the potential to reveal an economic phenomenon.

This paper is divided into five main sections. Section 2 provides some background information for this study and the development of the hypotheses. Section 3 outlines the design of the methodology. Sections 4 and 5 provide the results and describe how they can be used to extend existing market segmentation studies and practical implications. Lastly, Section 6 offers future research recommendations.

\section{Conceptual Background and Hypotheses Development}

\subsection{Generation Z}

Given that the Gen Z population is projected to comprise $32 \%$ of the global community of $7.7 \mathrm{billion}$ in 2019 [35] and will dominate the consumer market, marketers have largely overlooked this generation in trend research in recent years. A generation refers to a group of people who were born and live in the same time period and who have similar buying behaviors. The Gen $\mathrm{Z}$ cohort encompasses individuals born in or after 1995 [13] and who will experience a world different from all the preceding generations [36].

In general, Gen Zers are highly educated, tech-savvy, and community oriented. They have a strong sense of social responsibility, and 59\% of them express genuine interest in leading change in sustainable development [16]. They understand the "why" of being ecologically friendly but have difficulty in the "how" to get involved. Gen Z represents a sustainable food market segment with much potential, which is why gaining an understanding of its consumer group is vital to coordinating an effective approach to sustainability marketing.

\subsection{Market Segmentation}

Market changes and information technology advances bring with them new challenges and opportunities for market segmentation [12,37], making the correct use of segmentation in a marketing strategy essential to a company's success. The use of different basis variables in a segmentation approach provides more options to consider in the formulation of a marketing strategy, which counters the theory that there is only one basis for the segmentation of a market $[38,39]$. Research has identified four observable, consumer-based segmentation variables: cultural, geographical, demographical, and socioeconomical [39]. Observable product and service-based variables in connection to buying and consumption habits have also been identified. The variables identified include user status, frequency of use and brand and store loyalty and patronage, and the stage of adoption and situation of usage. Prior research also ascribes unobservable product and service-based variables to a "hierarchy of benefits", such as perceptions, attributes, preferences, and intentions [40].

In the food retail industry, market segmentation can be considered to be a customer-oriented process. The guiding principle of segmentation is to develop intra-segment homogeneity and inter-segment heterogeneity [41]. By so doing, management can concentrate on the needs of the most profitable market segments and develop offerings that not only satisfy those segments, but also help differentiate a company from its competitors [42]. Market segmentation development gives vendors the opportunity to increase sales by addressing the needs of customers in every cluster. As the probability of meeting the customer's needs increases, so will the likelihood of sales, according to Schiffman and Kanuk (2019) [43]. Thus, the need for segmentation has never been higher than it is today.

\subsection{Environmental Consciousness}

The current literature indicates that consumer inclinations toward being environmentally conscious in their purchasing decisions have ebbed and flowed in recent decades [44-48]; however, the longitudinal 
perspective shows that consumers and the corporations that serve them are gradually becoming more ecologically conscious, and, for many, the focus has moved from trend to core value. The most significant obstacle to the growth of the green economy and the successful use of environmentalism as a marketing tool is consumer understanding and acceptance of the concept of environmentalism [46].

Concern about the environment is no longer the province of a minority of environmental groups; consumers worldwide are genuinely concerned about environmental issues [2,49,50]. Environmental consciousness refers to individual and social group awareness and sensitivity toward the environment and related issues, including (a) the degree of concern for the environment, (b) sensitivity toward current or potential environmental problems, and (c) awareness of and responsible attitude toward ecological protection [51]. Some argue that the link between the environment and environmental or green marketing grew during the 1990s and 2000s, because the Baby Boom generation emerged as the primary consumer force $[47,52]$. By the late 1990 s, more than $50 \%$ of U.S. consumers were reading labels to determine if products were environmentally safe and were seeking out products and packaging made with recycled materials [52].

As more consumers in the U.S. and other Western countries come to view environmental and social responsibility as a given [47], the growing legions of environmentally conscious consumers have created a natural incentive for companies to meet those product and service needs. Based on the findings reported in Sections 2.1-2.3 of this paper, we propose the following hypotheses:

Hypothesis 1. U.S. Gen Z consumers can be segmented into distinct groups based on their level of environmental consciousness.

Hypothesis 2. Gen Z segments of the U.S. sustainable food market will differ with respect to sociodemographics with regard to (a) gender, (b) states of residence, and (c) racial or ethnic identity.

\subsection{Sustainable Food Attributes}

The concept of sustainable consumption has experienced rapid growth over the past three decades [30]. Sustainable consumerism has significantly influenced ecologically conscious decisions in various business segments and modified manufacturing processes and operation procedures $[33,53]$. As a result, the trends of sustainability are driving many businesses to adopt green marketing strategies through the development of products and services [2].

Consumer ecological purchase behaviors, however, differ from general purchase-related consumer behaviors [54]. Prior research has identified that individuals' concerns about the environment are critical factors motivating environmentally conscious behavior [55]. Food attributes that influence consumer choices have been studied in various green operational practices [56]; however, little information is available on sustainable food attributes (Sustainable food is defined as food that is healthy for consumers and produced in a humane, ecologically benign, socially responsible, and economically fair way (World Health Organization, 2004). Sustainable food production in this project includes, but is not limited to, organic, local, seasonal, fair trade, cage free, hormone free, third-party certified, and clean food and food-miles traveled.). Consequently, a more thorough understanding of the relationship between sustainable food attributes and consumer ecological behavior is necessary. Based on these findings, we propose the following hypothesis:

Hypothesis 3. Gen Z segments of the U.S. sustainable food market will differ with respect to the importance of the perception of sustainable food product attributes.

\subsection{Preference for Food Choices Associated with Healthy Eating Habits}

A study on Gen Z challenges conducted by the Institute of Emerging Issues at North Carolina State University (2015) [17] found that Gen Zers make health a priority when determining food choices 
and that they are willing to pay more for healthy foods. Raised on the concept that wellness is about holistic balance, Gen Zers may be the generation that reverses the worrying historic trend of expanding waistlines and a soaring incidence of lifestyle diseases. Dr. Denise Villa [17], a generational researcher, suggests that "Generation $\mathrm{Z}$ will know much more about healthy lifestyles, from a very young age, than any previous generation (2015, pp. 31)". As an increasing number of Gen Zers seek out healthier lifestyles than previous generations, understanding Gen Z's preference for food choices in this context is a critical factor in the successful marketing of sustainable development focused on market-by-market analysis. Based on this discussion, we propose the following hypothesis:

Hypothesis 4. Gen Z segments of the U.S. sustainable food market will differ with respect to preference for foods associated with healthy eating habits.

\section{Methodology}

\subsection{Sample and Data Collection}

The target population for this study was consumers who were born between 1995 and 2000 who purchase food items that provide social and environmental benefits, such as local food and educational opportunities, at least once a week in supermarkets or restaurants in the locations where they live or work. A study sample of 1000 consumers was provided by Survey Sampling International, Inc. (SSI). The national cross-section of 1000 consumers was chosen through a random sampling technique using a database of 1000 women and 1000 men, with all subjects having an equal chance of being chosen. SSI then invited panel members who had previously given SSI permission to include them in the survey to participate via email invitations. A link to the online questionnaire was provided in the invitation email from SSI.

A self-administered questionnaire was emailed to randomly selected U.S. females $(n=500)$ and males $(n=500)$. Participation in the study was voluntary, and respondents were informed about investigation confidentiality and of their rights. To incentivize response and increase the return rate of the emails, respondents who returned a completed questionnaire were rewarded with $\$ 2$ compensation. Four weeks after initiating data collection, 812 completed questionnaires were processed, yielding a response rate of $81 \%$. The data were then tabulated and subjected to statistical analysis.

\subsection{Research Instrument}

Data collection was made via a questionnaire, which was designed to elicit responses from male and female U.S. residents between 18 and 23 years of age who purchase sustainable foods in a grocery store or have a sustainable meal at a restaurant at least once a week. The self-administered mail questionnaire was constructed with regard to respondents' (a) environmental consciousness, which was measured using a composite score of the environmental involvement and value of purchasing environmentally friendly products scales; (b) perception of sustainable food attributes; (c) food choices associated with healthy eating habits; and (d) demographic characteristics.

The preliminary version of the questionnaire was pre-tested for comprehension of instructions and terminology using a web survey with a convenience sample $(n=20)$ and then refined based on the findings and suggestions of the pre-test group. The revised questionnaire was quantitatively pilot tested with a referral sample $(n=105)$, who were not members of the pre-test of U.S. Gen Zers, to gain information about the data collection process, test the questionnaire for comprehension of instructions and terminology, and assess the reliability of the measures. Based on the findings of the pilot test group, the questionnaire was accepted and formatted. Three primary constructs were measured: environmental consciousness, sustainable food attributes, and food choices; see Table 1. 
Table 1. Major constructors of the study.

\begin{tabular}{c}
\hline Environmental Consciousness \\
Environmental involvement \\
Environmental values for purchasing environmentally friendly products \\
\hline Importance of perception of sustainable food \\
Environmental protection \\
Product attributes \\
\hline Food choices associated with healthy eating habits
\end{tabular}

The first section of the questionnaire was constructed to gauge the degree of environmental awareness of the given Gen Zer. Four statements were derived from instruments developed by Schuhwerk and Lefkoff-Hagius (1995) [57] and were rated on a five-point Likert-type scale ranging from $5=$ strongly agree to $1=$ strongly disagree. The response statements were as follows: (a) I am concerned about the environment; (b) the condition of the environment affects the quality of my life; (c) I am willing to make sacrifices to protect the environment; and (d) my actions impact the environment.

The value of purchasing environmentally friendly products was obtained in the second section of the questionnaire. Twelve statements adopted from the study of Laroche, Bergeron, and Barbaro-Forleo (2001) [58] were included. Each was assessed on a five-point Likert-type scale ranging from $5=$ very important to 1 = very unimportant. Motives for purchasing environmentally friendly products were gathered from responses to the following statement: buying environmentally friendly products can (a) give me an environmental self-reliant feeling, (b) give me a feeling of contributing to environmental protection, (c) stimulate my environmental awareness, (d) give me a feeling of practicing the goal of self-environmental protection, (e) contribute to a healthy and happy life, (f) bring spiritual and peace of mind, (g) promote my social status, (h) increase symbiotic relationships with other organisms, (i) enhance my respect for the environment, (j) give hope for the future environment, (k) contribute to the conservation of nature, and (l) reduce damage to the environment.

The third section of the questionnaire elicited information on Gen Zers' perceptions about product attributes associated with sustainable foods. A perception of sustainable food attributes was comprised of two parts: (a) environmental protection [59,60] and (b) product characteristics [61,62]. Semantic differential items, 24 in total, were used, anchoring the five-place response format. The environmental protection attributes were as follows: sustainable foods (a) help to protect the environment, (b) prevent unnecessary animal suffering, (c) reduce the use of artificial fertilizers in agriculture, (d) reduce the eutrophication of lakes and watercourses, (e) reduce the pollution of the soil, and (f) reduce the use of herbicides and pesticides in agriculture. Product characteristics attributed to sustainable foods included the following: no pesticides; no hormones or genetically modified ingredients; no additives; use of natural ingredients; no artificial ingredients; and perception of being a trend, a fad, fraudulent, expensive, cheap, good value for money, easily available in supermarkets or restaurants, healthier, safer, fresher, and having better quality and taste than conventional foods.

The fourth section elicited information regarding the respondents' food choices for their healthy eating habits. Eight questions developed by Chen (2007) [63] were used, including the following: it is important to me that the food I eat on a typical day is (a) healthy and nutritious, (b) high in vitamins and minerals, (c) high in protein, (d) high in fiber and roughage, (e) low in calories, (f) low in fat, (g) low in sodium, and (h) contains no additives.

In the last section of the questionnaire, information about respondents' demographic characteristics was obtained and included the following: (a) gender, (b) residential region, and (c) ethnic background. 


\subsection{Statistical Analysis}

A preliminary version of the questionnaire was pre-tested for instruction and terminology comprehension using a web survey with a convenience sample of Gen Zers in the Southwestern U.S. $(n=20)$. It was then refined based on the findings and suggestions of the pre-test group. The revised questionnaire was quantitatively pilot tested with a referral sample $(n=50)$ of Gen Zers between 18 and 23 years of age living in the continental U.S. who were not members of the pre-test group in order to obtain information about the data collection process, test the questionnaire for instruction and terminology comprehension, and assess the reliability of the measures. Cronbach's alpha coefficient was calculated to measure the internal consistency of environmental involvement ( $\alpha=0.87)$, with environmental values $(\alpha=0.93)$, sustainable food attributes $(\alpha=0.87)$, and food choice scales $(\alpha=0.85)$. Cronbach's alpha levels were found to be within an acceptable range.

The first step in the analyses of the hypotheses was the development of a typology of Gen Zers based on 16 environmental consciousness items (Hypothesis 1). A principal component analysis with varimax rotation was conducted independently to determine the core dimensions of each of the three scales (environmental consciousness, sustainable food attributes, and food choices) to identify factors. The appropriateness of the factor analysis was assessed by a reliability alpha test. Items with a factor loading equal to or greater than 0.60 were considered significant. To further analyze the factor analysis, the Kaiser-Meyer-Olkin measure of sampling adequacy (KMO) was used. Higher values of KMO suggest that the data are adequate to be used in factor analysis [64]. The KMO for this study was 0.90; therefore, data from this study was very adequate for use in the factor analysis. Alternatively, Bartlett's test of sphericity aids in the determination of the significance of all correlations found within the correlation matrix [65]. With respect to Bartlett's test of sphericity, this study yielded a significance level of 5342.2, which indicates a high correlation.

Data obtained from the sustainable food attributes and food choice scales were analyzed statistically using the IBM Statistical Package for the Social Sciences (SPSS) ${ }^{\circledR}$ software version 25 for each scale. All statistical tests were considered significant at a level of 0.05 . to assess the validity of instrument scales [66,67]. Cronbach's alpha reliability coefficient was calculated to evaluate the internal consistency of the measurement scales and descriptive statistics; means, standard error and deviations, and frequency distributions were calculated to describe the sample. Hypothesis 1 was answered by employing a cluster analysis. Hypotheses 2, 3, and 4 were answered by univariate analysis, the chi-square test of independence and the multivariate analysis of variance (MANOVA), and one-way analysis of variance (ANOVA).

\section{Results}

\section{Description of the Sample}

While the target population was Gen Z consumers who were all 18-23 years of age, no majority age range for the sample was noted. Participants in the sample $(n=812)$ consisted of females $(53.6 \%)$ and males $(46.4 \%)$ and single $(51.6 \%)$ and married $(48.4 \%)$ people. In terms of residential region, participants resided in the South (33.3\%), Midwest (26.1\%), West $(23.4 \%)$, and Northeast $(17.2 \%)$ regions of the United States. A total of $72 \%$ had some college or a higher education degree. A total of $75 \%$ were White, non-Hispanic. A total of $22 \%$ earn annual household incomes of US $\$ 50,000-74,999$. In terms of employment status, more than half of respondents were unemployed or part-time workers. The sociodemographic information for the total sample is shown in Table 2. 
Table 2. Sociodemographics of the sample $(n=812)$.

\begin{tabular}{|c|c|c|c|}
\hline & Profile & Frequency & Percentage \\
\hline \multirow{2}{*}{ Gender } & Male & 377 & 46.4 \\
\hline & Female & 435 & 53.6 \\
\hline \multirow{4}{*}{ Residential Region } & Northeast & 140 & 17.2 \\
\hline & Midwest & 212 & 26.1 \\
\hline & South & 270 & 33.3 \\
\hline & West & 190 & 23.4 \\
\hline \multirow{3}{*}{ Employment Status } & Employed full-time & 119 & 17.7 \\
\hline & Employed part-time & 336 & 45.1 \\
\hline & Unemployed & 327 & 40.2 \\
\hline \multirow{7}{*}{ Education Level } & Some high school & 21 & 2.6 \\
\hline & High school diploma & 164 & 20.2 \\
\hline & Vocational/Technical school & 41 & 5.0 \\
\hline & Some college & 279 & 34.4 \\
\hline & Undergraduate degree (B.S., B.A., etc.) & 276 & 34 \\
\hline & Some graduate work & 26 & 3.2 \\
\hline & Graduate degree (M.S., M.B.A., Ph.D., Ed.D., etc.) & 5 & 0.6 \\
\hline \multirow{2}{*}{ Marital Status } & Single & 419 & 51.6 \\
\hline & Married & 393 & 48.4 \\
\hline \multirow{11}{*}{ Household Income } & Under $\$ 15,000$ & 95 & 11.7 \\
\hline & $\$ 15,000-24,999$ & 83 & 10.2 \\
\hline & $\$ 25,000-34,999$ & 113 & 13.9 \\
\hline & $\$ 35,000-49,999$ & 143 & 17.6 \\
\hline & $\$ 50,000-74,999$ & 175 & 21.6 \\
\hline & $\$ 75,000-99,999$ & 114 & 14.0 \\
\hline & $\$ 100,000-124,999$ & 37 & 4.6 \\
\hline & $\$ 125,000-149,999$ & 24 & 3.0 \\
\hline & $\$ 150,000-174,999$ & 10 & 1.2 \\
\hline & $\$ 175,000-199,000$ & 6 & 0.7 \\
\hline & $\$ 200,000$ and over & 12 & 1.5 \\
\hline \multirow{6}{*}{ Ethnicity } & African American & 73 & 9.0 \\
\hline & Asian & 40 & 4.9 \\
\hline & Hispanic & 67 & 8.3 \\
\hline & Native American & 8 & 1.0 \\
\hline & White, Non-Hispanic & 606 & 74.6 \\
\hline & Other & 18 & 2.2 \\
\hline
\end{tabular}

Hypothesis 1 addressed how U.S. Gen Z consumers can be segmented in terms of environmental consciousness and the differences that exist among groups. Subjects were classified into homogeneous environmental consciousness groups with similar characteristics using hierarchical agglomerative cluster analysis with Ward's method (1963) [68]. To answer Hypothesis 1, respondents were classified as having high environmental consciousness, moderate environmental consciousness, or low environmental consciousness, using the environmental involvement and environmental values scales. The classification procedure included calculating each participant's mean score for the environmental involvement scale and listing the means from low to high. Multivariate analysis determined differences were evident $(F=11.60, p<0.01$ ) between pairs of these groups (G1 and G2, G1 and G3, and G2 and G3 in the case of three groups).

The smallest was Group 1, with 58 subjects, or $7.1 \%$. It also had the lowest mean rating on all three factors (environmentally practical, environmentally supportive, and environmentally social) compared with the other groups. Group 2 was the second largest, with 373 subjects or $45.9 \%$. Group 3 was the largest, with 381 subjects, or $46.9 \%$. Subjects in Group 2 scored higher on all three of the factors, with Group 3 scoring higher on all three of the environmental consciousness factors than Group 1 but lower 
than Group 2. Table 3 shows the final cluster solution, size of each respondent group and the groups' mean choice set for each environmental consciousness factor. Relative classifications (high, moderate, and low) are also provided, in addition to the actual choice set mean.

Table 3. Cluster groups based on environmental consciousness.

\begin{tabular}{ccccccccc}
\hline $\begin{array}{c}\text { Environmental } \\
\text { Consciousness Factors }\end{array}$ & \multicolumn{2}{c}{$\begin{array}{c}\text { Group 1 } \\
(\mathbf{n}=\mathbf{5 8})\end{array}$} & \multicolumn{2}{c}{$\begin{array}{c}\text { Group 2 } \\
\mathbf{( n = 3 7 3 )}\end{array}$} & $\begin{array}{c}\text { Group 3 } \\
\mathbf{( n = 3 8 1 )}\end{array}$ & Univariate & Multivariate \\
\cline { 2 - 9 } & $\mathbf{M}$ & $\mathbf{S D}$ & $\mathbf{M}$ & $\mathbf{S D}$ & $\mathbf{M}$ & $\mathbf{S D}$ & $\mathbf{F}$ & $\mathbf{F}$ \\
\hline Environmentally Practical & 2.56 & 0.93 & 4.45 & 0.50 & 3.95 & 0.49 & $322.53^{* *}$ & $11.60^{* *}$ \\
Environmentally Supportive & 2.20 & 0.83 & 4.48 & 0.45 & 3.94 & 0.48 & $539.93^{* *}$ & \\
Environmentally Social & 1.60 & 0.65 & 3.87 & 0.55 & 2.64 & 0.58 & $651.55^{* *}$ & \\
\hline
\end{tabular}

${ }^{*} \mathrm{p}<0.05,{ }^{* *} \mathrm{p}<0.01$; Environmental consciousness scale: a. Environmental involvement scale: $5=$ strongly agree;

4 = agree; 3 = neutral; 2 = disagree; 1 = strongly disagree; $b$. Environmental values scale: 5 = very important;

$4=$ important; 3 = neutral; 2 = unimportant; 1 = very unimportant.

Following discriminant analysis of the environmental consciousness scales, the three U.S. Gen Z consumer groups were named. Group $1(\mathrm{n}=58)$ was identified as sustainable moderates, Group 2 $(\mathrm{n}=373)$ as sustainable activists, and Group $3(\mathrm{n}=381)$ as sustainable believers (Table 4$)$.

Table 4. Environmental consciousness profiles.

\begin{tabular}{cccc}
\hline \multirow{2}{*}{$\begin{array}{c}\text { Environmental Consciousness } \\
\text { Group (Size) }\end{array}$} & \multicolumn{3}{c}{ Relative Classifications of Means } \\
\cline { 2 - 4 } & $\begin{array}{c}\text { Environmentally } \\
\text { Practical }\end{array}$ & $\begin{array}{c}\text { Environmentally } \\
\text { Supportive }\end{array}$ & $\begin{array}{c}\text { Environmentally } \\
\text { Social }\end{array}$ \\
\hline Group 1: Sustainable Moderates & Moderate & Moderate & Low \\
$(\mathrm{n}=58)$ & $(2.20)$ & $(2.56)$ & $(1.60)$ \\
Group 2: Sustainable Activists & High & High & Moderate \\
$(\mathrm{n}=373)$ & $(4.48)$ & $(4.45)$ & $(3.87)$ \\
Group 3: Sustainable Believers & High & High & Low \\
$(\mathrm{n}=381)$ & $(3.94)$ & $(3.95)$ & $(2.64)$ \\
\hline
\end{tabular}

A profile of the sample is given in Table 5. Included in the demographic profile are gender, residential region, and ethnic background. Significant differences were found (noted in Table 5) for the main effects of gender $\left(X^{2}=14.84,[\mathrm{df}=2], p=0.001\right)$ and residential region $\left(X^{2}=10.81,[\mathrm{df}=4]\right.$, $p=0.001)$.

Table 5. Crosstab analysis for sociodemographics across environmental consciousness cluster groups.

\begin{tabular}{cccc}
\hline Sociodemographics & $\begin{array}{c}\text { Sustainable Moderates } \\
(\mathbf{n}=\mathbf{5 8})\end{array}$ & $\begin{array}{c}\text { Sustainable Activists } \\
(\mathbf{n}=\mathbf{3 7 3})\end{array}$ & $\begin{array}{c}\text { Sustainable Believers } \\
\mathbf{( n = 3 8 1 )}\end{array}$ \\
\hline Gender*** & Male & Female & Female \\
Residential Region & South & West & Midwest \\
Ethnicity & White, Non-Hispanic & White, Non-Hispanic & White, Non-Hispanic \\
\hline & \multicolumn{2}{c}{$p<0.05 ;{ }^{* *} p<0.01 ;{ }^{* *} p<0.001}$.
\end{tabular}

The results of MANOVA and univariate analyses on the sustainable food attributes scale are shown in Table 6. Hypothesis 3 was accepted, based on scale factor differences. Overall significant differences (multivariate $\mathrm{F}=15.32, p<0.01$ ) were found across the groups in sustainable food attributes. Differences were noted among groups in every category-environmental protection, health, price, attitude, and convenience. Sustainable moderates had the lowest mean score in environmental protection and health, which was significantly different from the other two groups. Sustainable activists and sustainable believers had similar perceptions about price, attitude, and convenience, but were very different from sustainable moderates. Moderates considered sustainable foods expensive and 
inconvenient to buy (as in, not widely available.) Sustainable activists and believers also consider the purchase of sustainable food to be beneficial to environmental protection and health.

Table 6. Multivariate and univariate analysis of differences across environmental consciousness cluster groups for sustainable food attributes.

\begin{tabular}{ccccccccc}
\hline Scale Factors & \multicolumn{2}{c}{$\begin{array}{c}\text { Sustainable } \\
\text { Moderates } \\
(\mathbf{n}=\mathbf{5 8})\end{array}$} & \multicolumn{2}{c}{$\begin{array}{c}\text { Sustainable } \\
\text { Activists } \\
(\mathbf{n}=\mathbf{3 7 3})\end{array}$} & $\begin{array}{c}\text { Sustainable } \\
\text { Believers } \\
(\mathbf{n = 3 8 1 )}\end{array}$ & Univariate & Multivariate \\
\cline { 2 - 9 } & $\mathbf{M}$ & $\mathbf{S D}$ & $\mathbf{M}$ & $\mathbf{S D}$ & $\mathbf{M}$ & $\mathbf{S D}$ & $\mathbf{F}$ & $\mathbf{F}$ \\
\hline Environmental Protection & 2.76 & 1.07 & 4.18 & 0.57 & 3.70 & 0.56 & $154.74^{* *}$ & $15.32^{* *}$ \\
Health & 2.50 & 1.15 & 3.97 & 0.71 & 3.34 & 0.73 & $124.09^{* *}$ & \\
Price & 3.58 & 1.03 & 2.61 & 0.96 & 2.81 & 0.81 & $027.96^{* *}$ & \\
Attitude & 3.58 & 1.03 & 2.61 & 0.96 & 2.81 & 0.81 & $027.96^{* *}$ & \\
Convenience & 3.58 & 1.03 & 2.61 & 0.96 & 2.81 & 0.81 & $027.96^{* *}$ &
\end{tabular}

${ }^{*} p<0.05,{ }^{* *} p<0.01$; Sustainable food attributes scale: $5=$ strongly agree; $4=$ agree; $3=$ neutral; $2=$ disagree; $1=$ strongly disagree.

Referring to Table 7 , an overall significant difference (multivariate $\mathrm{F}=4.63, p<0.01$ ) existed across groups regarding food choices. Sustainable moderates and believers were similar with respect to preferences for nutrition and health but differed significantly from sustainable activists.

Table 7. Multivariate and univariate analysis of differences across environmental consciousness cluster groups for food choices.

\begin{tabular}{ccccccccc}
\hline Scale Factors & $\begin{array}{c}\text { Sustainable } \\
\text { Moderates } \\
(\mathbf{n}=\mathbf{5 8 )}\end{array}$ & \multicolumn{2}{c}{$\begin{array}{c}\text { Sustainable } \\
\text { Activists } \\
(\mathbf{n}=\mathbf{3 7 3})\end{array}$} & $\begin{array}{c}\text { Sustainable } \\
\text { Believers } \\
(\mathbf{n}=\mathbf{3 8 1})\end{array}$ & Univariate & Multivariate \\
\cline { 2 - 9 } & $\mathbf{M}$ & $\mathbf{S D}$ & $\mathbf{M}$ & $\mathbf{S D}$ & $\mathbf{M}$ & $\mathbf{S D}$ & $\mathbf{F}$ & $\mathbf{F}$ \\
\hline Nutrition & 3.55 & 0.82 & 4.36 & 0.53 & 3.92 & 0.55 & $87.21^{* *}$ & $4.63^{* *}$ \\
Health & 3.50 & 0.98 & 4.04 & 0.78 & 3.57 & 0.80 & $35.96^{* *}$ & \\
\hline
\end{tabular}

${ }^{*} p<0.05,{ }^{* *} p<0.01$; Means with letters are NOT statistically different at alpha levels of $0.05^{*}$; Sustainable food attributes scale: 5 = strongly agree; $4=$ agree; $3=$ neutral; $2=$ disagree; $1=$ strongly disagree.

\section{Discussion, Conclusions, and Implications}

Grocers and other food retailers seek better ways to tailor their marketing, advertising, and promotional activities to their customers' specific market segments. Unfortunately, the precise identifiers needed to predict group membership are often lacking. This analysis provides support for the assumption that (a) the sustainable food market can be segmented according to the environmental awareness of a set of U.S. Gen Z consumers and (b) that Gen Z consumers decisions on the purchase of sustainable food can be influenced by the extrinsic and intrinsic sustainable food product attributes identified.

Marketing may be targeted with classification analysis by separating Gen $\mathrm{Z}$ consumers into categories based upon their level of environmental consciousness. Market share predictions can be based upon the contributions that the attributes of each food product make to the share. As a result, plans for product development and introduction, as well as market share predictions, can be developed based on a dataset that identifies group membership and individual characteristics. This study establishes that variable screening has the potential to more accurately segment and classify consumers' purchase of sustainable food. Market segmentation classification can benefit consumers through the availability of a merchandise mix that meets their preferences for products and usage. Segmentation research on the classification of food attributes in the sustainable food market can provide a greater understanding of consumer behavior. Additionally, as segmentation research relates to the social and 
environmental benefits of food products, such research can assist grocers, food retailers, and service operators in meeting consumer needs for specific product classification and healthy, sustainable food.

This study demonstrates that Gen Z consumer groups can be profiled through the use of environmental involvement and environmental values. The environmental involvement scale [58] and environmental values scale [59] used in this study both possessed high reliability, implying that these scales would be useful to marketers studying environmentally conscious consumers when clustering by environmental consciousness.

U.S. Gen $Z$ consumers were segmented into three distinct environmentally conscious groups: sustainable moderates $(7.1 \%)$, sustainable believers $(46.9 \%)$, and sustainable activists $(45.9 \%)$. The variables that distinguished the profile of each group were based on environmental involvement and values. It is evident that U.S. Gen $\mathrm{Z}$ consumers are becoming increasingly concerned about the environment (92.8\%) but that this growing environmental consciousness among consumers differs according to their level of concern for environmental issues and pro-sustainability behaviors. Those in "green" marketing should find the study of the environmentally conscious groups helpful in formulating a target strategy that relates to these findings.

Regarding the perception of sustainable food attributes, a higher percentage of Gen $\mathrm{Z}$ respondents $(92.8 \%)$ considered environmental protection and product characteristics related to health to be necessary to their purchase decisions for sustainable food. This suggests that the product attributes that can influence Gen $Z$ consumers' decisions to purchase sustainable foods may differ and that a marketing strategy that specifically targets distinctively eco-conscious Gen Z consumers is important, because sustainable activists, sustainable believers, and sustainable moderates placed different levels of importance on their choice of food. Sustainable activist Gen Z consumers considered food choices associated with healthy eating habits, such as eating food that is nutritious and healthy, to be more important than those consumers who show a lower degree of eco-consciousness (sustainable believers and moderates). In targeting highly eco-conscious Gen $\mathrm{Z}$ consumers, food retailers can use these findings to identify the product characteristics that associate attributes with environmental protection and health, for example, on labeling and advertising, as well as in the development of merchandising strategies.

\section{Limitations and Recommendations}

Consideration should be given to the limitations of this study, which may have impacted the results, because this study provides new and consequential information to the existing research about market segmentation. First, the use of samples comprising mainly Caucasian Americans is a limitation, given the growing emphasis placed on marketplace diversity as a critical component of target marketing strategies in the U.S. Future segmentation studies should identify and reflect a larger sample of ethnically diverse Gen Z consumers (i.e., Native Americans, African Americans, Asian Americans, and Hispanics). This approach could be useful in rendering more accurate segmentation influencers and enabling grocers, food retailers, and service operators to focus on the appropriate product attributes important to specific segments of their market. Findings based on a larger sample and with a higher response rate could also verify whether these results could be generally applied to a broader population.

Second, self-reported measures assessing sustainable food purchase intention and consumption behavior may contribute to over-reporting due to the effect of social desirability response bias. Self-reported behaviors may or may not reflect actual practices, as they are personal descriptions of one's actions. Therefore, temporal differences exist between consumption intention and behavior. This discrepancy many have contributed to the non-significant relationship between the two variables. Open-ended questions to elicit free response data from in-depth customer interviews, as well as focus-group sessions, should also be considered in future research. As a result of that data, product attributes could be described using the consumers' vocabulary. It could also be used to remediate the quantitative bias associated with pre-selected product attribute ratings and ranking scales. Responses would also reveal food product features that Gen $\mathrm{Z}$ consumers consider to be 
determinants of sustainable food. Finally, longitudinal studies to eliminate one-point-in-time response bias in order to develop a trend study would be of great interest to academics and practitioners.

Author Contributions: Conceptualization, C.-H.S., C.-H.T., and M.-H.C.; methodology, C.-H.S.; formal analysis, C.-H.S.; data collection, C.-H.T.; writing—original draft preparation, C.-H.S.; writing—review and editing, C.-H.S.; visualization, C.-H.S.; supervision, M.-H.C., and W.Q.L.

Funding: Iowa State University Faculty Startup Fund (Account No. 7061011).

Acknowledgments: This research was financially supported by the Iowa State University Faculty Startup Fund (Account No. 7061011). Additionally, the authors are sincerely grateful for the editors' and anonymous reviewers' comments and suggestions, which helped to improve the paper's quality.

Conflicts of Interest: The authors declare no conflicts of interest.

\section{References}

1. Rethink Education. Available online: https://academicearth.org/electives/academic-earth/ (accessed on 30 January 2018).

2. Martin, D.; Schouten, J. Sustainable Marketing; Pearson: London, UK, 2012; pp. 73-74.

3. Thogersen, J. Country differences in sustainable consumption: The case of organic food. J. Macromarket. 2010, 30, 171-185. [CrossRef]

4. Hu, H.H.; Parsa, H.G.; Self, J. The dynamics of green restaurant patronage. Cornell Hosp. Q. 2010, 51, 344-362. [CrossRef]

5. Mostafa, M.M. A hierarchical analysis of the green consciousness of the Egyptian consumer. J. Psychol. Market. 2007, 24, 445-473. [CrossRef]

6. Myung, E.; McClaren, A.; Li, L. Environmentally related research in scholarly hospitality journals: Current status and future opportunities. Int. J. Hosp. Manag. 2012, 31, 1264-1275. [CrossRef]

7. Schubert, F.; Kandampully, J.; Solnet, D.; Kralj, A. Exploring consumer perceptions of green restaurants in the US. Tour. Hosp. Res. 2010, 10, 286-300. [CrossRef]

8. Argyropoulos, C.; Tsiafouli, M.A.; Sgardelis, S.P.; Pantis, J.D. Organic farming without organic products. Land Use Pol. 2013, 32, 324-328. [CrossRef]

9. Chua, K.B.; Quoquab, F.; Mohammad, J.; Basiruddin, R. The mediating role of new ecological paradigm between value orientations and pro-environmental personal norm in the agricultural context. Asia Pac. J. Mark. Log. 2016, 28, 323-349. [CrossRef]

10. Svatošová, V. Green marketing-Motivation of environmental consumer behavior. China-Usa Bus. Rev. 2012, $11,1630-1646$.

11. Oakley, I.; Chen, M.; Nisi, V. Motivating sustainable behavior. In Proceedings of the 10th International Conference on Ubiquitous Computing, Seoul, Korea, 20-23 September 2008; pp. 8-12.

12. Sheth, J.N.; Sethia, N.K.; Srinivas, S. Mindful consumption: A customer-centric approach to sustainability. J. Acad. Market. Sci. 2011, 39, 21-39. [CrossRef]

13. Priporas, C.V.; Stylos, N.; Fotiadis, A. Generation Z consumers' expectations of interactions in smart retailing: A future agenda. Comput. Hum. Behav. 2017, 77, 374-381. [CrossRef]

14. Alphabet Soup: Boomers, Gen X, Gen Y, and Gen Z Explained. Available online: https://communityrising. kasasa.com/gen-x-gen-y-gen-z/ (accessed on 3 June 2018).

15. How Generation $Z$ will Change the World. Available online: http://time.com/5250542/generation- $z /$ (accessed on 24 August 2018).

16. Gen Z Survey. Available online: https://masdar.ae/en/strategic-platforms/youth-4-sustainability/gen-Zsurvey (accessed on 6 November 2018).

17. Investing in Gen Z. Available online: https:/iei.ncsu.edu/emerging-issues/ongoing-programs/generation-z/ (accessed on 19 November 2018).

18. Green Generation: Millennials Say Sustainability is a Shopping Priority. Available online: https://www.nielsen.com/us/en/insights/news/2015/green-generation-millennials-say-sustainabilityis-a-shopping-priority.html (accessed on 11 May 2018). 
19. How Much Financial Influence Does Gen Z Have? Available online: https://www.forbes.com/sites/jefffromm/ 2018/01/10/what-you-need-to-know-about-the-financial-impact-of-gen-z-influence/\#61c516bc56fc (accessed on 7 February 2019).

20. Key Differences between Gen Z and Millennials. Available online: https://www.huffingtonpost.com/georgebeall/8-key-differences-between_b_12814200.html (accessed on 5 November 2018).

21. Generation $\mathrm{Z}$ is Creating a $\$ 5$ Billion Market for Fake Meat and Seafood. Available online: http://www. businessinsider.com/generation-z-is-eating-fake-meat-2017-10 (accessed on 8 April 2018).

22. Xiao, C.; Dunlap, R.E. Validating a comprehensive model of environmental concern cross-nationally: A US-Canadian comparison. Soc. Sci. Quart. 2007, 88, 471-493. [CrossRef]

23. Environmental Imperative. Available online: https://www.qsrmagazine.com/sustainability/environmentalimperative (accessed on 29 November 2018).

24. Consumer Insights Into the Role of Sustainability, Health, the Environment and Social Responsibility: Understanding the LOHAS Market Report. Available online: http://www.lohas.se/wp-content/uploads/2015/ 07/Understanding-the-LOHAS-Consumer-11_LOHAS_Whole_Foods_Version.pdf (accessed on 12 October 2018).

25. Devinney, T.M.; Auger, P.; Eckhardt, G.M. The Myth of the Ethical Consumer; Cambridge University Press: Cambridge, UK, 2010; pp. 149-150.

26. Kilbourne, W.E.; Beckmann, S.C. Review and critical assessment of research on marketing and the environment. J. Mark. Manag. 2008, 14, 513-532. [CrossRef]

27. Straughan, R.D.; Roberts, J.A. Environmental segmentation alternatives: A look at green at green consumer behavior in the new millennium. J. Consum. Market. 2009, 16, 558-575. [CrossRef]

28. Hartmann, P.; Apaolaza-Ibanez, V. Consumer attitude and purchase intention toward green energy brands: The roles of psychological benefits and environmental concern. J. Bus. Res. 2012, 65, 1254-1263. [CrossRef]

29. Barbarossa, C.; De Pelsmacker, P. Positive and negative antecedents of purchasing eco-friendly products: A comparison between green and non-green consumers. J. Bus Ethics 2016, 134, 229-247. [CrossRef]

30. Peattie, K. Green consumption: Behavior and norms. Annu. Rev. Environ. Resou. 2010, 35, $195-228$. [CrossRef]

31. Pilgrim, S.E.; Smith, D.; Pretty, J. A cross-regional assessment of the factors affecting eco-literacy: Implications for policy and practice. Ecol. Applic. 2007, 17, 1742-1751. [CrossRef]

32. Joshi, Y.; Rahman, Z. Factors affecting green purchase behavior and future research directors. Int. Strat. Manag. Rev. 2015, 3, 128-143. [CrossRef]

33. Chen, C.C.; Chen, C.W.; Tung, Y.C. Exploring the consumer behavior of intention to purchase green products in belt and road countries: An empirical analysis. Sustainability 2018, 10, 854. [CrossRef]

34. Jahanshahi, A.A.; Jia, J. Purchasing green products as a means of expressing consumers' uniqueness: Empirical evidence from Peru and Bangladesh. Sustainability 2018, 10, 4062. [CrossRef]

35. Gen Z 2025: The Final Generation. Available online: https://www.slideshare.net/sparksandhoney/gen-Z2025-the-final-generation-preview (accessed on 21 February 2019).

36. Fishman, A. Who Comes After the Millennials?: A Case for Gen 9/11; American Marketing Association: Chicago, IL, USA, 2019.

37. Best, R.J. Market-Based Management: Strategies for Growing Customer Value and Profitability, 6th ed.; Pearson: London, UK, 2012.

38. Foedermayr, E.K.; Diamantopoulos, A. Market segmentation in practice: Review of empirical studies, methodological assessment and agenda for future research. J. Strat. Market. 2008, 16, 223-265. [CrossRef]

39. Kotler, P.; Keller, K.L. Marketing Management, 15th ed.; Pearson: London, UK, 2016.

40. McCabe, S. Marketing Communications in Tourism and Hospitality: Concepts, Strategies and Cases; Routledge: New York, NY, USA, 2009.

41. Morrison, A.M. Hospitality and Travel Marketing, 4th ed.; Delmar Learning: Clifton Park, NY, USA, 2010.

42. McDonald, M. Market Segmentation: How to do it, How to Profit from it, 4th ed.; Wiley: Hoboken, NJ, USA, 2010.

43. Schiffman, L.; Kanuk, L. Consumer Behavior, 12th ed.; Pearson: London, UK, 2019.

44. Pickett-Baker, J.; Ozaki, R. Pro-environmental products: Marketing influence on consumer purchase decision. J. Consum. Market. 2008, 25, 281-293. [CrossRef]

45. Review of Green Attitudes \& Behaviors of American Consumers. Available online: https://www.experian. com/marketing-services/marketing-services.html (accessed on 29 March 2018). 
46. Rohr, D.E. Environmentalism and the marketing of consumer products: Products linking corporate responsibility with sales opportunity. Contemp. Top Ecol. 2011, 2, 518-533.

47. Trivedi, R.H.; Patel, J.D.; Savalia, J.R. Pro-environmental behavior of consumers: A taxonomy and its implications for the green marketer. South Asian J. Manag. 2011, 18, 121-132.

48. Bemporad, R.; Baranowski, M. Conscious Consumers are changing the Rules of Marketing: Highlights from the BBMG Conscious Consumer Report; Bemporad Baranowski Marketing: Brooklyn, NY, USA, 2007.

49. Emery, B. Sustainable Marketing; Pearson: London, UK, 2012.

50. What is Environmental Conflict? Available online: http://www.css.ethz.ch/content/dam/ethz/special-interest/ gess/cis/center-for-securities-studies/pdfs/What_is_Environment_Conflict_1992.pdf (accessed on 17 March 2018).

51. Ottman, J.A. The New Rules of Green Marketing: Strategies, Tools, and Inspiration for Sustainable Branding; Greenleaf Publishing: Sheffield, UK, 2011.

52. Baby Boomers Still Got Game; Where Does that Leave Gen X, Gen Y? Available online: https://www. huffingtonpost.com/ira-wolfe/baby-boomers-still-got-ga_b_8025078.html (accessed on 4 December 2018).

53. Shrum, L.J.; McCarty, J.A.; Lowrey, T.M. Buyer characteristics of the green consumer and their implications for advertising strategy. J. Advert. 2013, 24, 71-82. [CrossRef]

54. Ellen, P.S.; Wiener, J.L.; Cobb-Walgren, C. The role of perceived consumer effectiveness in motivating environmentally conscious behavior. J. Public Policy Mark. 1991, 10, 102-117. [CrossRef]

55. Botonaki, A.; Polymeros, K.; Tsakiridou, E.; Mattas, K. The role of food quality certification on consumers' food choices. Brit. Food J. 2006, 108, 77-90. [CrossRef]

56. Vieregge, M.; Scanlon, N.; Huss, J. Marketing locally grown food products in globally branded restaurants. J. Foodserv. Bus. Res. 2007, 10, 69-82. [CrossRef]

57. Schuhwerk, M.E.; Lefkoff-Hagius, R. Green or non-green? Does type of appeal matter when advertising a green product? J. Advert. 1995, 24, 45-54. [CrossRef]

58. Laroche, M.; Bergeron, J.; Barbaro-Forleo, G. Targeting consumers who are willing to pay more for environmentally friendly products. J. Consum. Market. 2001, 18, 503-520. [CrossRef]

59. Magnusson, M.K.; Arvola, A.; Hursti, U.K.; Aberg, L.; Sjödén, P.O. Choice of organic foods is related to perceived consequences for human health and to environmentally friendly behavior. Appetite 2003, 40, 109-117. [CrossRef]

60. Rezai, G.; Teng, P.K.; Mohamed, Z.; Shamsudin, M.N. Consumers' awareness and consumption intention towards green foods. Afr. J. Bus. Manage. 2012, 6, 4496-4503.

61. Ogbeide, G.C.; Brunner, C.W.; Freshour, A.; Kinzler, T.; Bryant, L. Consumer perceptions of green restaurants in the twenty-first century. Hosteur 2009, 18, 11-15.

62. Roitner-Schobeserger, B.; Darnhofer, I.; Somsook, S.; Vogi, C.R. Consumer perceptions of organic foods in Bangkok, Thailand. Food Policy 2008, 33, 112-121. [CrossRef]

63. Chen, M.F. Consumer attitudes and purchase intentions in relation to organic foods in Taiwan: Moderating effects of food-related personality traits. Food Qual. Prefer. 2007, 18, 1008-1021. [CrossRef]

64. Kaiser, H.F.; Rice, J. An index of factorial simplicity. Psychometrika 1974, 39, 31-36. [CrossRef]

65. Hair, J.F.; Black, W.C.; Babin, B.J.; Anderson, R.E. Multivariate Data Analysis, 7th ed.; Pearson: London, UK, 2014.

66. Green, S.B.; Salkind, N.J. Using SPSS for Windows and Macintosh: Analyzing and Understanding Data, 8th ed.; Pearson: London, UK, 2017.

67. Vogt, P.W.; Johnson, R.B. Dictionary of Statistics \& Methodology: A Nontechnical Guide for the Social Science, 5th ed.; Sage: London, UK, 2016.

68. Ward, J.H. Hierarchical grouping to optimize an objective function. J. Am. Statist. Assoc. 1963, 58, $236-244$. [CrossRef]

(C) 2019 by the authors. Licensee MDPI, Basel, Switzerland. This article is an open access article distributed under the terms and conditions of the Creative Commons Attribution (CC BY) license (http://creativecommons.org/licenses/by/4.0/). 